\title{
POSIBILIDADES DE LA TERAPIA ANTIOXIDANTE EN DIABETES MELLITUS TIPO 2. ESTUDIO DEL ESTRÉS OXIDATIVO EN UNA MUESTRA POBLACIONAL DE PACIENTES DIABÉTICOS
}

\author{
Possibilities of the antioxidant therapy in type 2 diabetes mellitus. \\ Study of oxidative stress in a population sample of diabetic patients
}

\section{Rodolfo Núñez-Musaa, Alberto J. Núñez-Sellés ${ }^{b}$, Wilfredo Mañón Rossic, Rafael Guillén Marmolejos $^{d}$, Gregorio Martínez-Sánchez ${ }^{\mathrm{e}}$ y Antonio Selman-Almonte ${ }^{\mathrm{f}}$}

Recibido: 20 enero, $2020 \bullet$ Aprobado: 6 abril, 2020

Cómo citar: Núñez-Musa R, Núñez-Sellés AJ, Mañón Rossi W, Guillén Marmolejos R, Martínez-Sánchez G, Selman-Almonte A. Posibilidades de la terapia antioxidante en diabetes mellitus tipo 2. Estudio del estrés oxidativo en una muestra poblacional de pacientes diabéticos. cysa [Internet]. 18 de septiembre de 2020 [citado 18 de septiembre de 2020];4(3):71-93. Disponible en: https:// revistas.intec.edu.do/index.php/cisa/article/view/1917

\section{Resumen}

Introducción: el organismo se expone cotidianamente a diferentes agentes que provocan reacciones oxidativas normalmente controladas. La sobreproducción de especies reactivas del oxígeno y/o la deficiencia de antioxidantes lleva al estrés oxidativo (EO) asociado a patologías crónicas que contribuye a un peor pronóstico de las enfermedades. Una de esas patologías crónicas es la diabetes mellitus (DM), en la que se ha demostrado una gran participación del EO en su fisiopatología y en el desarrollo de complicaciones. Se determinó el índice de EO (IEO) en individuos con DM y en un grupo sano control, para evaluar su posible correlación y grado de daño oxidativo, como estrategia para justificar una intervención potencial con una terapia antioxidante adyuvante al tratamiento convencional.

\begin{abstract}
Introduction: The body exposes daily to different agents that cause normally controlled oxidative reactions. Overproduction of reactive oxygen species and/or decrease in antioxidants induce oxidative stress (OS) associated with chronic pathologies contribute to a worse prognosis of the disease. One such chronic pathology is diabetes mellitus (DM) in which OS has shown to be highly involved in its pathophysiology and as part of the development of complications. The OS index (OSI) was determined in individuals with DM and in a healthy control group, to assess their possible correlation and degree of oxidative damage, as an initial supportive strategy for a potential antioxidant therapy as an adjunction to conventional treatment
\end{abstract}

\footnotetext{
d Contract Research Organization CREODR, Santo Domingo, República Dominicana. Correo-e: rafaelgui218@gmail.com

e Consultor Independiente, Ancona, Italy. Correo-e: gregorcuba@yahoo.it

${ }^{\mathrm{f}}$ Contract Research Organization CREODR, Santo Domingo, República

Dominicana. Correo-e: $f$ ant.selman@claro.net.do
}

\footnotetext{
a Contract Research Organization CREODR, Santo Domingo, República ORCID: 0000-0002-8829-6648

b Universidad Nacional Evangélica (UNEV), República Dominicana. Correo-e: nunez500412@gmail.com

${ }^{\mathrm{c}}$ Contract Research Organization CREODR, Santo Domingo, República Dominicana. Correo-e: wmanonrossi@gmail.com
} 
Materiales y métodos: se midió IEO en una población de 110 individuos con DM, constituida por 37 casos de DM tipo 1 (DMT1) y 73 del tipo 2 (DMT2) en edades entre 50 y 70 ańos escogidos al azar y se comparó con los valores de un grupo control de voluntarios sanos. El objetivo del ensayo clínico fue definir el grado de correlación entre los niveles del IEO y la severidad del daño oxidativo, ponderado a partir de una fórmula cualitativa, a través de la medición de nueve biomarcadores del EO en lisados de eritrocitos.

Discusión: la prevención o la detención de las comorbilidades de la DM puede que descanse en el futuro en la identificación precisa de los biomarcadores y su contrapartida reguladora. La incorporación de una terapia utilizando un protocolo con antioxidantes $(\mathrm{AO})$ adyuvantes al manejo estándar de la DMT2 podría proveer resultados más eficaces para el control hiperglucémico y, por tanto, para inducir el equilibrio redox. Los resultados demuestran que ese tipo de terapia no sería eficaz en DMT1. Es determinante el reconocimiento de la extensión y tipo de daño oxidativo de las poblaciones específicas, mediante la creación y utilización de una línea de base con los biomarcadores alterados más frecuentemente. Esta línea de base ayudará a definir la mejor estrategia antioxidante a aplicar, porque el polimorfismo genético, el ambiente y los hábitos de vida actúan puntualmente en el tipo respuesta al EO. Una estrategia beneficiosa a valorar puede ser la del desarrollo de nuevos fármacos con efectos antioxidantes o de productos capaces de reforzar el sistema fisiológico de antioxidación a partir de sustratos naturales y la elaboración de combinaciones de dosis fijas de $\mathrm{AO}$ eficaces que ataquen las causas el $\mathrm{EO}$ en la DM. El objetivo final será el de revertir el daño oxidativo para prevenir la instalación de complicaciones o frenarlas.

Conclusiones: el uso del IEO con distintos marcadores ayuda a la especificidad del diagnóstico del EO, pero para que la elección de los marcadores sea la correcta, esta debe estar definida por el objetivo y el diseńo del estudio, así como por la relevancia clínica en los sujetos seleccionados, tal cual fue el aplicado en el ensayo realizado. Los resultados obtenidos demuestran la potencialidad del uso de la terapia antioxidante en DMT2, pero no así en la DMT1. La importancia clínica de los biomarcadores del EO en humanos debe provenir de un análisis crítico de los marcadores que refleje el estado general de redox en condiciones particulares y una orientación para una terapia antioxidante efectiva.

Palabras clave: estrés oxidativo; índice de estrés oxidativo; biomarcadores; terapia antioxidante; diabetes mellitus.
Methods: OSI was measured in a population of 110 individuals with DM, consisting of 37 cases of type $1 \mathrm{DM}$ (DMT1) and 73 type 2 (DMT2) at ages between 50 and 70 years chosen at random and compared with the values of a healthy volunteer control group. The main goal of the clinical trial was to define the degree of correlation between OSI levels and oxidative damage severity, weighted from a qualitative formula, through the measurement of nine OS biomarkers in erythrocyte lysate.

Discussion: The prevention or detention of DM comorbidities may rest in the future in the precise identification of biomarkers and their regulatory counterpart. The inclusion of a therapy using an antioxidant protocol adjuvant to the standard management of DMT2 could provide more effective results for hyperglycemic control and, therefore, to induce redox balance. The results show that this type of therapy would not be effective in DMT1. The recognition of the extent and type of oxidative damage in specific populations is decisive, through the creation and use of a baseline with the most frequently altered biomarkers. This baseline will help defining the best antioxidant strategy to be applied, because genetic polymorphism, the environment and styles of life act specifically in the type of response to the OS. A beneficial scheme to assess may be the development of new drugs with antioxidant effects or products capable of strengthening the physiological antioxidant system made from natural substrates and the making of effective fixed dose combinations of antioxidants that attack the causes of OS in DM. The final aim is to reverse oxidative damage in order to prevent the appearance of complications or slow them down.

Conclusions: The use of OSI with different biomarkers helps to achieve the specificity of OS diagnosis, but for the choice of markers to be correct, these must be defined by the objective and design of the study, as well as by the clinical relevance in the selected subjects, as was the one applied in the actual trial. The results obtained demonstrate the potentiality of the use of antioxidant therapy in DMT2, but not in DMT1. The clinical importance of OS biomarkers in humans should come from a critical marker's analysis that reflects the overall status of redox under particular conditions and guidance for effective antioxidant therapy.

Keywords: Oxidative Stress; Oxidative Stress Index; Biomarkers; Antioxidant Therapy; Diabetes Mellitus. 


\section{Introducción}

Producto del metabolismo, de forma fisiológica, el organismo produce especies reactivas de oxígeno (ERO) dentro de las cuales están los radicales libres, que contienen un número desigual de electrones en su último orbital y por lo cual producen reacciones químicas en cadena y así oxidan las bio-moléculas. Las defensas AO actúan amortiguando (reduciendo) las ERO gracias a su capacidad de donar un electrón a un radical libre sin hacerse inestables, de modo que el efecto oxidativo no sea dañino. La perturbación de este sistema se conoce como estrés oxidativo (EO). La pérdida del estado normal de reducción-oxidación (redox) puede causar efectos tóxicos a través del tiempo y el consiguiente deterioro bioquímico y biomolecular de la célula, incluyendo el ADN.

Las ERO juegan su rol fisiológico en el sistema redox para la seńalización molecular, con lo cual se inician y se regulan numerosos procesos. Dentro de estos procesos se cuentan la activación de las vías de la proteína-quinasa mitogénica activada y la quinasa activada por señalización extracelular, partes del sistema de transmisión de señales para la regulación del crecimiento celular normal que alteran la expresión genética, en coordinación con la superóxido dismutasa, e inician la muerte celular ${ }^{1}$. Por ello, cuando los niveles de ERO sobrepasan los límites normales, provocando EO, las alteraciones resultantes impactan sistémicamente al organismo.

Las ERO se pueden generar de fuentes endógenas (respiración mitocondrial, activación de macrófagos y neutrófilos, entre otras) o exógenas (radiaciones ionizantes, exposición a químicos, producto del metabolismo de fármacos, humo de cigarrillos, contaminantes ambientales o industrial, entre otros). En condiciones normales, el organismo responde a los incrementos patológicos de las ERO con $\mathrm{AO}$ en forma natural o adquiriéndolos exógenamente.
La diabetes mellitus (DM) es una enfermedad conocida desde la antigüedad egipcia con una fisiopatología que comprende una serie de desórdenes metabólicos cuya mayor expresión es la hiperglucemia crónica. El desarrollo de la enfermedad va acompañado, sobre todo en casos no tratados, de complicaciones agudas y crónicas y, entre estas últimas, son relevantes la enfermedad cardiovascular (ECV), la nefropatía, neuropatía y retinopatía diabéticas. En sentido general, la insulina es el eje básico en la patogenia debido a una producción ineficiente de la misma, en la que se ubican los casos de diabetes mellitus tipo 1 (DMT1), o a una mala respuesta de los tejidos periféricos a su acción en los casos de diabetes mellitus tipo 2 (DMT2), aunque no exclusivamente para esta última. La complejidad de los procesos celulares que participan en la fisiopatología plantea problemas de efectividad terapéutica, por lo que ordinariamente hay que multimedicar a los pacientes.

El EO ha sido ligado a la etiopatogénesis de una gran cantidad de patologías y entre ellas la DM es una de las más estudiadas y relacionadas ${ }^{2-7}$.

En la DMT2 confluyen múltiples daños fisiológicos, pero el deterioro progresivo de la función de las células $\beta$ en los islotes de Langerhans y la insulino-resistencia constituyen el punto de quiebre en el control efectivo de la enfermedad. Por estos cambios fisiológicos los pacientes presentan una mala tolerancia a la glucosa y la producción de glucosa hepática en ayunas es inapropiadamente alta, que se manifiestan como intolerancia a la glucosa y e hiperglucemia ( $\mathrm{HG}$ ), que gradualmente se instalan y permanecen al pasar los años.

Las ERO, en concentraciones fisiológicas, son esenciales para las vías de señalización y la $\mathrm{HG}$ es una de las causas que las elevan; en ciertas condiciones de incremento fisiológico de oxidantes celulares, las citoquinas y los bisulfitos de tioles intercambian reacciones provocando que algunas proteínas actúen 
como interruptores redox, que por lo general ocurre en forma reversible en condiciones normales ${ }^{2}$. El problema es que la aparición de EO excesivo provocará oxidación irreversible e indiscriminada de los sustratos que actúan como antioxidantes, daño y luego muerte celular.

En DMT2 la formación de ERO ocurre tanto en exceso como a largo plazo, causando el EO crónico responsable, en gran medida, de la expresión genética y la secreción defectuosas de la insulina, como también de una aumentada apoptosis celular ${ }^{3}$. Las ERO también causan oxidación por la generación de mecanismos que interfieren con ciertos procesos intracelulares, como la autofagia, la misma apoptosis y la sobreproliferación celular ${ }^{4}$.

A nivel de las células $\beta$ pancreáticas, la disponibilidad de oxígeno, la glucólisis (aeróbica o anaeróbica) y la producción de ERO están íntimamente ligados a su papel fisiológico, a la sensibilidad a la glucosa y a la liberación de insulina. La alteración resultante de la acción de los ERO sobre la cadena de eventos que determinan la función de las células $\beta$, puede tener un papel determinante en la disfuncionalidad y muerte de estas células 5 . Por tanto, la producción excesiva o la remoción defectiva de estos radicales libres conducen a los daños de carácter progresivo, a veces irreversible, de las microestructuras celulares a través del deterioro de sus funciones más elementales a nivel molecular.

En el caso de DMT2, las complicaciones asociadas a EO parecen relacionarse al exceso de ERO debido a una falla en su ritmo de destrucción y/o a un aumento en la producción de catalasa, superóxido dismutasa y glutatión-peroxidasa, lo cual hace susceptibles a los tejidos al EO y, en consecuencia, a las complicaciones de la diabetes ${ }^{6}$, en particular las vasculares, que son la mayor causa de comorbilidad y muerte en DMT2.
El EO resultante de la excesiva producción de ERO explica mucho de la patogénesis de la DM, tanto 1 como 2, donde la glicosilación no enzimática de proteínas, la gluco-oxidación y la elevada peroxidación lipídica causan daño mayormente irreversible de las enzimas y la maquinaria celular que terminan por instalar la insulino-resistencia como eje central de la fisiopatología diabética ${ }^{7}$.

Diversos estudios han mostrado que la determinación de biomarcadores concretos permiten dilucidar con gran seguridad cuáles de estos biomarcadores tienen suficiente especificidad para el diagnóstico temprano de patologías asociadas con DMT2, tanto como para valorar la intensidad del daño crónico ${ }^{8,9}$

Las estrategias farmacológicas para manejo de la DMT2 se apoyan en modificaciones de los estilos de vida, priorizando la reducción de la resistencia insulínica y la HG, así como el control, la reducción o la contención de la dislipidemia, el EO, la inflamación y la obesidad como fórmula integral para mejorar las expectativas y la calidad de vida. Las opciones de tratamiento de la DM están estandarizadas con base en insulina inyectable y a hipoglucemiantes orales. La primera línea de tratamiento de estos últimos (DTM2) es una biguanida (metformina), que reduce la gluconeogénesis hepática y la lipogénesis, disminuye la absorción intestinal de glucosa y mejora la sensibilidad de la insulina. La segunda línea de tratamiento lo constituyen las sulfonilureas (glimepirida, glipizida y gliclazida) que aumentan la secreción de insulina regulada por los canales de potasio sensibles a ATP localizados en la membrana de las células beta del páncreas. Las meglitinidas (repaglinida y nateglinida) tienen un mecanismo de acción similar a las sulfonilureas, pero se absorben más rápidamente, con una duración menor del efecto. Las tiazolidinedionas (rosiglitazone y pioglitazone), que incrementan la asimilación periférica de la glucosa y disminuyen la producción de glucosa hepática, 
constituyen otra opción de tratamiento. Los inhibidores de la 4-dipeptidil peptidasa (DPP-4), tales como la sitagliptina, saxagliptina, vildagliptina, linagliptina y alogliptina y de los co-transportadores de la glucosa sódica (SGLT2), tales como la dapagliflozina y canagliflozina son alternativas más recientes de este arsenal farmacológico en el tratamiento de la DMT2 ${ }^{10}$.

Existe una evidencia en la literatura científica, cada vez mayor, de que el EO juega un papel importante en las complicaciones de la $\mathrm{DM}^{3-7}$. La HG incrementa el EO, lo que favorece el deterioro de los procesos fisiológicos y disminuye la eficacia de los mecanismos de defensa antioxidante, lo cual contribuye a elevar el $\mathrm{EO}^{8}$. Se puede inferir un posible efecto beneficioso de una terapia antioxidante en el manejo de la DM, tanto para mejorar el estado del paciente como para retardar o eliminar la aparición de las complicaciones de la $\mathrm{DM}^{11,12}$. La comprensión cada vez mejor de los procesos ultramoleculares y sus efectos macro en el organismo permiten reconocer un rol más puntual del $\mathrm{EO}$ en procesos vitales, como la regulación de las señalizaciones genéticas que gobiernan las respuestas normales o patológicas a nivel tisular.

En este estudio se presentan los resultados de la determinación del IEO en una población de adultos diabéticos como el paso inicial para crear una línea basal general, a partir de la cual se pueda dar apoyo terapéutico, nutricional o de suplementación a los pacientes diabéticos de forma específica y tal vez causal.

\section{Material y métodos}

\section{- Diseńo metodológico y deontología médica}

El diseño de la investigación clínica consistió en un estudio de cohorte en una muestra de 110 individuos diabéticos conocidos, de ambos sexos, con edades entre 50 y 70 ańos, con el fin de evaluar prospectivamente el IEO. Los sujetos fueron seleccionados en las consultas de Medicina Familiar de los Hospitales "Marcelino Vélez Santana” y "Padre Billini” sitos en la ciudad de Santo Domingo, República Dominicana, ya que el más reciente estudio epidemiológico indicó que la mayor concentración de diabéticos se encuentra en esta provincia ${ }^{13}$. Un grupo control integrado por 123 voluntarios sanos fue escogido en varias comunidades de la misma ciudad.

La determinación del tamaño de la muestra, con el fin de obtener resultados significativos, se realizó utilizando XLSTAT-Biomed para muestreo estadístico, teniendo en cuenta la incidencia de DM en el grupo de edad seleccionado en la población de Santo Domingo.

Para el estudio se conformaron dos grupos y dos subgrupos: el grupo I para control y el grupo II para los sujetos de estudio. El tamaño del universo seleccionado se estableció con el fin de obtener un nivel de significancia $\alpha=0.05$, potencia $(1-\beta)=0.2$, desviación estándar $(\mathrm{o})=2$ y detección de la diferencia $(d)=1$. El total de individuos reclutados fue de 233.

Los pacientes y el reclutamiento de voluntarios sanos se llevaron a cabo a través de un Consentimiento Informado, de acuerdo con la Declaración de Helsinki y se hizo en el período mayo-agosto de 2019. Los asistentes de investigación explicaron el propósito del estudio a pacientes y voluntarios sanos, y el consentimiento informado se firmó con la presencia de un testigo. Toda la información sobre la identidad de los sujetos se estableció como confidencial y se utilizaron códigos para identificar registros clínicos y muestras. El protocolo para el ensayo clínico fue aprobado por la Comisión Nacional de Bioética en Salud (CONABIOS) con el número de registro 008-2016. 


\section{- Criterios de inclusión y exclusión}

Los pacientes fueron seleccionados al azar a su llegada a la consulta y se les aplicaron los siguientes criterios de entrada al estudio:

1. Adultos de ambos sexos con diagnóstico confirmado de diabetes I y II según los criterios de la Asociación Americana de Diabetes-ADA (Estándares de la Atención Médica en Diabetes 2019)

2. Dos años o más de evolución de la enfermedad (DMT2)

\section{No fumadores}

4. No consumidores regulares de alcohol o estupefacientes según la Guía Internacional para Vigilar el Consumo de Alcohol y sus Consecuencias Sanitarias de la Organización Mundial de la Salud (WHO/MSD/MSB/00.4)

5. No consumo de $\mathrm{AO}$ en los últimos doce meses

Fueron excluidos los voluntarios que llenaran uno o más de los siguientes criterios: presencia de enfermedad crónica degenerativa intercurrente, consumo de bebidas alcohólicas o sustancias estupefacientes regularmente, consumo de bebidas alcohólicas o sustancias estupefacientes durante el estudio y participación en otro estudio.

Durante un período de seis meses fueron reclutados los individuos y todos, tanto los del grupo de estudio como los controles, fueron evaluados clínicamente. Una muestra de sangre de $100 \mu \mathrm{L}$ fue tomada a cada sujeto y registrada en el Cuaderno de Registro de Datos (CRD) bajo un código específico de identificación.

\section{- Manejo de las muestras}

Las muestras de sangre se obtuvieron mediante punción del pulpejo del dedo y colectada en tubos de Eppendorf de sellado hermético, con $2 \mathrm{~mL}$ de solución salina normal. Las muestras se conservaron por 24 horas a $8{ }^{\circ} \mathrm{C}$ hasta su destino final al laboratorio de Estrés Oxidativo de la Universidad Nacional Evangélica (UNEV). Se procedió a su centrifugación sin removerlas del tubo a $3000 \mathrm{~g}$, el supernadante se eliminó y se agregaron $2 \mathrm{~mL}$ de agua bidestilada a la fracción de eritrocitos remanente para inducir la hemólisis. Una vez hemolizada la muestra, se separó una fracción de $200 \mu \mathrm{L}$ con el uso de una micropipeta y fue llevada a un tubo de Eppendorf de $1 \mathrm{~mL}$ y almacenada a $-10^{\circ} \mathrm{C}$ en un congelador vertical hasta su procesamiento final en los próximos 60 días.

\section{- Procedimientos de laboratorio}

Luego de los 60 días, todas las muestras fueron procesadas en UNEV para identificar los nueve biomarcadores del EO, según se detallan en el cuadro siguiente:

\begin{tabular}{|c|c|}
\hline Biomarcador & Determinación \\
\hline $\begin{array}{l}\text { Potencial de } \\
\text { Peroxidación } \\
(\mathrm{PP})\end{array}$ & $\begin{array}{l}\text { Incubación del lisado de eritrocitos (LE) con } \\
\mathrm{CuSO}_{4} \text { II }(2 \mathrm{mM}) \text { a } 37^{\circ} \mathrm{C} \text { por } 24 \mathrm{~h} \text { para determi- } \\
\text { nación el MDA en tiempo } 0 \text { y } 24 \text { horas }^{15} \text {. La dife- } \\
\text { rencia constituyó el PP. }\end{array}$ \\
\hline $\begin{array}{l}\text { Estatus } \\
\text { Antioxidante } \\
\text { Total (EAT) }\end{array}$ & $\begin{array}{l}\text { Medición a través de la cinética de los ERO con el } \\
\text { catión 2,2'-azinobis-(3-etilbenzotiazolina-6-ácido } \\
\text { sulfónico (ABTS+) a } 600 \mathrm{~nm}^{16} \text {. }\end{array}$ \\
\hline $\begin{array}{l}\text { Capacidad } \\
\text { Antioxidante } \\
\text { Equivalente } \\
\text { al Trolox } \\
\text { (TEAC). }\end{array}$ & $\begin{array}{l}\text { LE incubado con una solución amortiguadora } \\
\text { de acetato sódico }(40 \mathrm{mM}, \mathrm{pH}=5.5) \text { y } 1 \mathrm{~mL} \\
\text { de etanol por una hora a } 37^{\circ} \mathrm{C} \text {. Luego se añade } \\
1 \mathrm{~mL} \text { de } 1,1 \text {-difenil-2-picrilhidrazil }(\mathrm{DFPH}) \\
100 \mu \mathrm{M} \text { a una alícuota de la muestra incubada } \\
\text { y la absorbancia a } 517 \mathrm{~nm} \text { se define para ambas } \\
\text { alícuotas (con y sin DFPH })^{17} \text {. }\end{array}$ \\
\hline $\begin{array}{l}\text { Prueba de } \\
\text { Malondialde- } \\
\text { hído (MDA). }\end{array}$ & $\begin{array}{l}\text { LE analizado con el kit LPO- } 586 \text { (Calbiochem, La } \\
\text { Jolla, CA, USA). Se cuantifica la producción de un } \\
\text { cromóforo estable a } 586 \mathrm{~nm} \text { después de } 40 \text { min de } \\
\text { incubación a } 45^{\circ} \mathrm{C} \text {. Estandarización: soluciones } \\
\text { recién preparadas de MDA-bis[dimetilacetal] cuan- } \\
\text { tificadas bajo condiciones idénticas }{ }^{18} \text {. }\end{array}$ \\
\hline
\end{tabular}




\begin{tabular}{|c|c|}
\hline $\begin{array}{l}\text { Grupos } \\
\text { Carbonilos } \\
\text { (GC). }\end{array}$ & $\begin{array}{l}\text { LE suspendido en } 1 \mathrm{~mL} \text { de } \mathrm{HCl}(2 \mathrm{M}) \text { y } 1 \mathrm{~mL} \\
\text { de } 2,4 \text {-dinitrofenilhidrazina }(0.2 \%) \text { e incubado } \\
\text { con agitación a } 37^{\circ} \mathrm{C} \text { por } 1 \text { hora. Añadido } 1 \mathrm{~mL} \\
\text { de } \mathrm{C}_{2} \mathrm{HCl}_{3} \mathrm{O}_{2}(10 \%) \text { y extracción del precipitado } \\
\text { con } 10 \mathrm{~mL} \text { de etanol-etilacetato al } 1: 1 \text {. Sedimento } \\
\text { reprecipitado con } \mathrm{C}_{2} \mathrm{HCl}_{3} \mathrm{O}_{2}(10 \%) \text {. Muestra } \\
\text { control de albúmina de huevo disuelta en } 1 \mathrm{~mL} \\
\text { de hidrocloruro de guanidina en solución amorti- } \\
\text { guadora } \mathrm{K}_{2} \mathrm{HPO}_{4}(20 \mathrm{mM} \text {, pH }=6.5)^{19} \text {. Centrifu- } \\
\text { gado de ambos y la absorbancia determinada a } 370 \\
\text { y } 375 \mathrm{~nm} \text {. }\end{array}$ \\
\hline $\begin{array}{l}\text { Grupos } \\
\text { Sulfhidrilo } \\
\text { (GS). }\end{array}$ & $\begin{array}{l}\text { LE disuelto en } 1 \mathrm{~mL} \text { de solución amortiguadora de } \\
\mathrm{K}_{2} \mathrm{HPO}_{4}(50 \mathrm{mM}, \mathrm{pH}=7.5) \text { y centrifugado. Reac- } \\
\text { ción del sobrenadante con el reactivo de Ellman y } \\
\text { la absorbancia determinada a } 600 \mathrm{~nm} \text {. Igual proce- } \\
\text { dimiento para la muestra control de albúmina de } \\
\text { huevo no oxidada }{ }^{20} \text {. }\end{array}$ \\
\hline $\begin{array}{l}\text { Superóxido } \\
\text { Dismutasa } \\
\text { (SOD). }\end{array}$ & $\begin{array}{l}\text { LE mezclado con } 2.8 \mathrm{~mL} \text { de una solución amor- } \\
\text { tiguadora de TRIS }(0.05 \mathrm{M}, \mathrm{pH}=8.2), 100 \mu \mathrm{L} \text { de } \\
\text { agua destilada y } 50 \mu \mathrm{L} \text { de una solución de EDTA } \\
(1 \mathrm{mM}) \text {. Agregados } 50 \mu \mathrm{L} \text { de una solución de piro- } \\
\text { galol }(0.124 \mathrm{M}) \text { y absorbancia determinada a } 420 \\
\text { nm después de } 10 \text { s y cada } 10 \text { s por un minuto } \\
(6 \text { lecturas })^{21} \text {. Igual procedimiento aplicado a una } \\
\text { preparación en blanco sin muestra de LE. }\end{array}$ \\
\hline $\begin{array}{l}\text { Catalasa } \\
\text { (CAT). }\end{array}$ & $\begin{array}{l}\text { LE mezclado en una celda de cuarzo con } 0.9 \mathrm{~mL} \\
\text { de solución amortiguadora de } \mathrm{K}_{2} \mathrm{HPO}_{4}(\mathrm{pH}=7) \text { y } \\
500 \mu \mathrm{L} \text { de una solución de } \mathrm{H}_{2} \mathrm{O}_{2}(0.05 \mathrm{M}) \text { en solu- } \\
\text { ción amortiguadora }{ }^{22} \text {. Determinada la absorbancia } \\
\text { a } 240 \mathrm{~nm} \text { en los tiempos } 10 \text { y } 70 \mathrm{~s} \text {, y la absorbancia } \\
\text { del blanco con } 1.5 \mathrm{~mL} \text { de solución amortiguadora. } \\
\text { Se mide la diferencia de absorbancias para ambas } \\
\text { muestras y la actividad de la CAT. }\end{array}$ \\
\hline $\begin{array}{l}\text { Gluta- } \\
\text { tión-Peroxi- } \\
\text { dasas (GPx) }\end{array}$ & $\begin{array}{l}\text { La GPx cataliza la reducción del sustrato hidrope- } \\
\text { róxido de cumeno y oxida el GSH. En presencia de } \\
\text { glutatión reductasa y NADPH el GSSG es conver- } \\
\text { tido inmediatamente a su forma reducida con una } \\
\text { oxidación paralela de NADPH a NADP+ }{ }^{23} \text {. Se } \\
\text { mide la disminución en la absorbancia a } 340 \mathrm{~nm} \text {. } \\
\text { Los resultados se expresan como U/g Hb. }\end{array}$ \\
\hline
\end{tabular}

Notas:

1. Todos los valores se llevaron a una escala normalizada de 100 unidades y cada muestra se analizó por triplicado y los resultados expresados como $(\overline{\mathbf{Y}}) \pm \mathrm{SD}$.

2. Reactivos y disolventes de Sigma Aldrich (USA) o JT Baker (USA), excepto donde se explica lo contrario.
3. Los valores de absorbancia se determinaron con un Genesis 10S, Thermo Scientific, EE. UU., con celdas de cuarzo de $1 \mathrm{~cm}$ de profundidad

4. La incubación se realizó con platos desechables de Petri (Fisherbrand, EE. UU.) en una incubadora DNI-150 (MRC, Israel)

5. Las muestras se centrifugaron con una centrífuga MiniSpin (Eppendorf, Alemania)

6. Las muestras de sangre se recogieron con AutoLancets (Palcolabs, EE. UU.) y se recogieron en viales de PVC de 0.5, 1 y $2 \mathrm{ml}$ de Eppendorf.

\section{- Manejo de los datos}

Con los datos de las pruebas experimentales realizadas en las muestras de sangre de todos los sujetos, se procedió a su tabulación segregadas para cada subgrupo y para el grupo testigo. De forma individual se calculó el IEO aplicando la fórmula siguiente:

$$
\operatorname{IEO}(\%)=\left[\frac{\mathrm{n}^{1} \mathrm{M}_{i}^{\mathrm{A}}+\mathrm{n}^{2} \mathrm{M}_{i}^{\mathrm{B}}+\mathrm{n}^{3} \mathrm{M}_{\mathrm{i}}^{\mathrm{C}}}{\mathrm{n}^{1}+\mathrm{n}^{2}+\mathrm{n}^{3}}\right]_{\mathrm{G}}
$$

Donde:

$$
\mathrm{M}_{\mathrm{i}}^{\mathrm{A}}=\frac{\sum T_{A}^{D M}}{\sum T_{A}^{\text {SANOS }}} \cdot 100
$$$$
\mathrm{M}_{\mathrm{i}}^{\mathrm{B}}=\frac{\sum T_{B}^{D M}}{\sum T_{B}^{S A N O S}} \cdot 100
$$$$
\mathrm{M}_{\mathrm{i}}^{\mathrm{C}}=\frac{\sum T_{C}^{D M}}{\sum T_{C}^{\text {SANOS }}} \cdot 100
$$ 
$\mathrm{n}^{1}=3$ Número de biomarcadores para determinar la concentración total de radicales libres: PP, EAT y TEAC

$\mathrm{n}^{2}=3$ Número de biomarcadores específicos del daño oxidativo celular/tisular: MDA, GC, GS

$\mathrm{n}^{3}=3$ Número de biomarcadores específicos de las enzimas endógenas para la defensa antioxidante: SOD, CAT, GPx

G Género ( $\mathrm{M}$ o $\mathrm{F})$ y grupo etario (1: 60-64; 2: $\geq 65$ ańos de edad)

El procesamiento estadístico, así como las tabulaciones y cotejo de data experimental, fue realizada por dos técnicos estadísticos independientes y no conectados entre sí, quienes elaboraron tablas en y sometieron resultados en duplicado. Para el análisis estadístico de la información obtenida en los grupos y subgrupos se empleó el programa estadístico SPSS 9.0. Se hicieron pruebas no paramétricas de Friedman para algunos subgrupos relacionados $y$, para el examen de cambios dentro de grupos y subgrupos, se usó el test pareado de Wilconxon. Con el propósito de estimar diferencias estadísticas $(\mathrm{p}<0.05)$ entre los subgrupos se aplicó la prueba de Mann-Whitney U. ambos técnicos emplearon las mismas técnicas y reportaron los resultaron como valores medios \pm media de desviación estándar (MDE).

El Grado de Daño Oxidativo (GDO) se calculó como el porcentaje de IEO determinado en los subgrupos versus el IEO obtenido en los voluntarios sanos. La ponderación de estos valores fue estandarizada según lo siguiente:

$$
\begin{aligned}
\text { IEO GDO } \\
0 \text { Ninguno } \\
<30 \text { Ligero } \\
30-60 \text { Moderado } \\
>60 \text { Severo }
\end{aligned}
$$

\section{Resultados}

En comparación con el grupo II, el grupo control mostró similares valores con respecto a la edad, etnia y distribución de género. La edad promedio fue de 67.0 años. El grupo étnico fue predominantemente negro y mestizo y oscilaron entre 49.6 y $30.1 \%$, respectivamente, lo que significaba el 79.7 $\%$ del grupo control. Para el grupo II, lo valores fueron de y 30.9 y $40.0 \%$ respectivamente, para un total de $70.9 \%$ para el grupo II. El género femenino predominó en ambos grupos (tablas $1 \mathrm{y}$ 2). Desde el punto de vista étnico y de género, no hubo diferencias significativas entre los grupos.

La tabla 3 muestra los resultados de la determinación del IEO en el Grupo I, repartidos según sexo y rangos de edad. En la última columna se resume el IEO de cada rango de edad. Los valores más altos correspondieron al grupo etario $\geq 65$ años tanto en hombres como en mujeres.

Tabla 1. Edad promedio y género de los grupos de estudio

\begin{tabular}{|c|c|c|c|c|}
\hline Grupos & $\begin{array}{c}\text { Mascu- } \\
\text { lino }\end{array}$ & $\begin{array}{c}\text { Feme- } \\
\text { nino }\end{array}$ & Total & $\begin{array}{c}\text { Media de } \\
\text { edad }\end{array}$ \\
\hline Grupo I & $\mathbf{5 1}$ & $\mathbf{7 2}$ & $\mathbf{1 2 3}$ & $\mathbf{6 6 . 8} \pm 3.0$ \\
\hline Grupo II & $\mathbf{4 1}$ & $\mathbf{6 9}$ & $\mathbf{1 1 0}$ & $\mathbf{6 5 . 9} \pm 4.0$ \\
\hline $\begin{array}{c}\text { Subgrupo IIa } \\
\text { (DMT 1) }\end{array}$ & 13 & 24 & 37 & $\mathbf{6 6 . 0 \pm 3 . 9}$ \\
\hline $\begin{array}{c}\text { Subgrupo } \\
\text { IIb (DMT2) }\end{array}$ & 28 & 45 & 73 & $\mathbf{6 5 . 8} \pm 4.0$ \\
\hline TOTAL & $\mathbf{9 2}$ & $\mathbf{1 4 1}$ & $\mathbf{2 3 3}$ & $\mathbf{6 4 . 4} \pm \mathbf{3 . 5}$ \\
\hline
\end{tabular}

DMT1: Diabetes mellitus tipo 1. DTM2: Diabetes mellitus tipo 2. No se encontraron diferencias significativas para las variables sexo y edad entre los grupos I y II.

Fuente: elaboración propia.

78 | Ciencia y Salud 2020; 4(3, septiembre-diciembre): Casos clínicos • 71-93 
Tabla 2. Composición étnica de los grupos de estudio

\begin{tabular}{|c|c|c|c|c|c|c|}
\hline Grupos & & Blancos & Negros & Mestizos & Asiáticos & Total \\
\hline Grupo I & No. & 23 & 61 & 37 & 2 & \\
\hline & $\%$ & 18.7 & 49.6 & 30.1 & 1.6 & 123 \\
\hline Grupo II & No. & 32 & 34 & 44 & $\mathbf{0}$ & \\
\hline & $\%$ & 29.1 & 30.9 & 40.0 & $\mathbf{0}$ & 110 \\
\hline Subgrupo IIa (DMT1) & No. & 10 & 12 & 15 & 0 & \\
\hline & $\%$ & 27.0 & 32.4 & 40.5 & $\mathbf{0}$ & $3 /$ \\
\hline Subgrupo IIb (DMT2) & No. & 22 & 22 & 29 & 0 & \\
\hline & $\%$ & 30.1 & 30.1 & 39.7 & $\mathbf{0}$ & 13 \\
\hline TOTAL & No. & 55 & 95 & 81 & 2 & \\
\hline & $\%$ & 23.6 & 40.8 & 34.8 & 0.8 & 233 \\
\hline
\end{tabular}

DMT1: Diabetes mellitus tipo 1. DTM2: Diabetes mellitus tipo 2. No se encontraron diferencias significativas para las etnias entre los grupos I y II.

Tabla 3. Caracterización del Índice de Estrés Oxidativo en el Grupo I

\begin{tabular}{|c|c|c|c|c|c|}
\hline \multirow{2}{*}{ Género } & Rangos de edad & Término $\mathrm{m}_{\mathrm{i}}^{\mathrm{a}}$ & Término $\mathrm{m}_{\mathrm{i}}^{\mathrm{b}}$ & Término $\mathrm{m}_{\mathrm{i}}^{\mathrm{c}}$ & $\begin{array}{c}\mathrm{IEO} \pm \mathrm{sd} \\
(\mathrm{p}<0.05)\end{array}$ \\
\hline \multirow{2}{*}{$\mathrm{M}$} & $60-64$ & $11.0 \pm 2.3$ & $10.8 \pm 1.3$ & $9.0 \pm 1.3$ & $30.7 \pm 3.3$ \\
\cline { 2 - 6 } & $\geq 65$ & $14.0 \pm 2.4$ & $14.7 \pm 1.9$ & $11.5 \pm 1.6$ & $40.2 \pm 5.7^{\mathrm{b}}$ \\
\hline \multirow{2}{*}{$\mathrm{F}$} & $60-64$ & $10.7 \pm 1.6$ & $10.8 \pm 1.9$ & $9.2 \pm 1.4$ & $30.7 \pm 5.4$ \\
\cline { 2 - 6 } & $\geq 65$ & $13.3 \pm 1.2$ & $14.6 \pm 2.0$ & $12.1 \pm 1.5$ & $40.0 \pm 4.8^{\mathrm{a}}$ \\
\hline
\end{tabular}

IEO: Índice de Estrés Oxidativo (ver materiales y métodos); $\mathrm{M}_{\mathrm{i}}^{\mathrm{A}}=\mathrm{A}_{1}(\mathrm{PP})+\mathrm{A}_{2}(\mathrm{EAT})+\mathrm{A}_{3}(\mathrm{TEAC}) ; \mathrm{M}_{\mathrm{i}}^{\mathrm{B}}=\mathrm{B}_{1}(\mathrm{MDA})+$ $\mathrm{B}_{2}(\mathrm{GC})+\mathrm{B}_{3}(\mathrm{GS}): \mathrm{M}_{\mathrm{i}}^{\mathrm{C}}=\mathrm{C}_{1}(\mathrm{SOD})+\mathrm{C}_{2}(\mathrm{CAT})+\mathrm{C}_{3}(\mathrm{GPx})$; PP: Potencial de Peroxidación, TAS: Estatus Antioxidante Total, TEAC: Capacidad Antioxidante Equivalente al Trolox, GS: Grupo Sulfihidrilo; MDA: Malondialdehído, SOD: Superóxido Dismutasa, CAT: Catalasa, GPx: Glutatión Peroxidasas. Diferentes letras en superíndice significan diferencia estadística $(\mathrm{p}<0,05)$ entre las mimas series.

Fuente: elaboración propia. 
Los valores altos de IEO en la totalidad de los individuos del grupo I (valores entre 30 y 40 para una escala de 100) para ambos géneros, se pueden explicar, al menos en parte, por el papel de las ERO en el proceso de envejecimiento ${ }^{22}$. No se encontraron diferencias significativas $(\mathrm{p}>0.05)$ en IEO cuando se consideraron las etnias.

La tabla 4 detalla los valores en cada grupo y subgrupo de casos en los diabéticos incluidos en el estudio. Esta tabla muestra que entre ambos grupos de pacientes diabéticos hubo diferencia significa- tiva. Los valores fueron mayores en el rango de edad 60-64 años, en ambos subgrupos.

Los resultados de la determinación del IEO en el subgrupo IIa no fueron significativos, excepto para las mujeres mayores de 65 años de edad, en las que el IEO fue más bajo. Aunque se encontraron diferencias significativas $(\mathrm{p}<0.05)$ para cada término independiente de la ecuación IEO, la desviación estándar fue considerablemente mayor al determinar el valor del IEO.

Tabla 4. Resultados de la determinación del IEO en el grupo II y sus subgrupos

\begin{tabular}{|c|c|c|c|c|c|}
\hline GÉNERO & $\begin{array}{c}\text { RANGOS DE } \\
\text { EDAD }\end{array}$ & TERM $M_{I}^{A}$ & TERM $M_{I}^{B}$ & TeRM $M_{I}^{c}$ & $\begin{array}{l}\mathrm{IEO} \pm \mathrm{SD} \\
(\mathrm{p}<0.05)\end{array}$ \\
\hline \multicolumn{6}{|c|}{ DMT1 (SUBGRUPO IIA) } \\
\hline \multirow{2}{*}{$\mathbf{M}$} & $60-64$ & $17.4 \pm 2.6$ & $17.6 \pm 1.9$ & $11.2 \pm 1.0$ & $33.0 \pm 6.8$ \\
\hline & $\geq 65$ & $24.4 \pm 2.8^{\mathrm{a}}$ & $24.8 \pm 1.8^{\mathrm{a}}$ & $17.0 \pm 1.4^{\mathrm{a}}$ & $29.0 \pm 8.6$ \\
\hline \multirow{2}{*}{$\mathbf{F}$} & $60-64$ & $20.9 \pm 2.6$ & $22.0 \pm 1.8$ & $14.5 \pm 1.4$ & $30.3 \pm 7.6$ \\
\hline & $\geq 65$ & $26.9 \pm 2.5^{\mathrm{ab}}$ & $28.1 \pm 1.5^{\mathrm{ab}}$ & $20.9 \pm 1.5^{\mathrm{ab}}$ & $26.1 \pm 8.8^{\mathrm{a}}$ \\
\hline \multicolumn{6}{|c|}{ DMT2 (SUBGRUPO IIB) } \\
\hline \multirow{2}{*}{$\mathbf{M}$} & $60-64$ & $24.4 \pm 1.8$ & $24.8 \pm 1.4$ & $17.0 \pm 2.1$ & $53.4 \pm 3.5^{b}$ \\
\hline & $\geq 65$ & $26.9 \pm 2.7$ & $28.1 \pm 2.7$ & $20.9 \pm 3.8$ & $46.1 \pm 7.2^{c}$ \\
\hline \multirow{2}{*}{$\mathbf{F}$} & $60-64$ & $23.8 \pm 1.2$ & $24.3 \pm 1.5$ & $16.9 \pm 2.3$ & $52.4 \pm 3.6^{c}$ \\
\hline & $\geq 65 y$ & $25.7 \pm 1.9$ & $27.1 \pm 2.2$ & $20.1 \pm 3.7$ & $43.9 \pm 6.1^{\mathrm{abc}}$ \\
\hline
\end{tabular}

IEO: Índice de Estrés Oxidativo (ver materiales y métodos); $\mathrm{M}_{\mathrm{i}}^{\mathrm{A}}=\mathrm{A}_{1}(\mathrm{PP})+\mathrm{A}_{2}(\mathrm{EAT})+\mathrm{A}_{3}(\mathrm{TEAC}) ; \mathrm{M}_{\mathrm{i}}^{\mathrm{B}}=\mathrm{B}_{1}(\mathrm{MDA})+$ $\mathrm{B}_{2}(\mathrm{GC})+\mathrm{B}_{3}(\mathrm{GS}): \mathrm{M}_{1}^{\mathrm{C}}=\mathrm{C}_{1}(\mathrm{SOD})+\mathrm{C}_{2}(\mathrm{CAT})+\mathrm{C}_{3}(\mathrm{GPx})$; PP: Potencial de Peroxidación, TAS: Estatus Antioxidante Total, TEAC: Capacidad Antioxidante Equivalente al Trolox, GS: Grupo Sulfihidrilo; MDA: Malondialdehído, SOD: Superóxido Dismutasa, CAT: Catalasa, GPx: Glutatión Peroxidasas. Diferentes letras en superíndice significan diferencia estadística $(\mathrm{p}<0,05)$ entre las mimas series.

Fuente: elaboración propia.

80 | Ciencia y Salud 2020; 4(3, septiembre-diciembre): Casos clínicos • 71-93 
Se estimó el GDO en los pacientes del grupo II con relación al grupo control (tabla 5). En el subgrupo IIa el GDO se determinó como leve, mientras que en el subgrupo IIb fue moderado y aunque fue más elevado en el grupo etario 60-64 años en ambos subgrupos, no hubo diferencia significativa entre ellos.

Tabla 5. Determinación de GDO en los subgrupos a y b según el IEO en el Grupo II

\begin{tabular}{|c|c|c|c|c|c|}
\hline \multirow{2}{*}{ Género } & $\begin{array}{c}\text { Rango de } \\
\text { edad }\end{array}$ & $\begin{array}{c}\text { Subgrupo } \\
\text { IIa }\end{array}$ & GDO & $\begin{array}{c}\text { Subgrupo } \\
\text { IIb }\end{array}$ & GDO \\
\hline \multirow{4}{*}{ M } & $60-64$ & $\begin{array}{c}33.0 \pm \\
6.8\end{array}$ & leve & $53.4 \pm 3.5^{\mathrm{b}}$ & moderado \\
\cline { 2 - 6 } & $\geq 65$ & $\begin{array}{c}29.0 \pm \\
8.6\end{array}$ & leve & $46.1 \pm 7.2^{\mathrm{c}}$ & moderado \\
\hline \multirow{3}{*}{$\mathrm{F}$} & $60-64$ & $\begin{array}{c}30.3 \pm \\
7.6\end{array}$ & leve & $52.4 \pm 3.6^{\mathrm{c}}$ & moderado \\
\cline { 2 - 6 } & $\geq 65$ & $\begin{array}{c}26.1 \pm \\
8.8^{\mathrm{a}}\end{array}$ & leve & $\begin{array}{c}43.9 \pm \\
6.1^{\mathrm{abc}}\end{array}$ & moderado \\
\hline
\end{tabular}

GDO: Grado de Daño Oxidativo. Diferentes letras en superíndice significan diferencia estadística $(\mathrm{p}<0.05)$ entre las mimas series.

Fuente: elaboración propia.

\section{Discusión}

Con la determinación de estos biomarcadores para $\mathrm{EO}$, por primera vez en una población dominicana sana, se ha examinado el daño oxidativo por encima de los 60 años de edad. Los biomarcadores utilizados incluyen, no solo la sobreproducción de radicales libres (Término A), sino el daño oxidativo de las biomoléculas (Término B) y la actividad de las enzimas relacionadas con el mecanismo endógeno de defensa antioxidante (Término C).

Estudios previos han señalado la importancia de este tipo de determinación experimental con el fin de correlacionar la asociación entre el EO y la progresión de la enfermedad en el tratamiento estándar a través de un conjunto de biomarcadores, lo que puede conducir a la comprensión del equilibrio corporal redox en la salud humana ${ }^{24}$. Específicamente, estos resultados se utilizaron para determinar la IEO en pacientes con DM, comparando su grado de EO con el del grupo control y, objetivamente, se empleó una batería de biomarcadores, en apoyo a la hipótesis de otros investigadores de que un IEO calculado a partir de un conjunto de biomarcadores debe ser mejor que un solo biomarcador para caracterizar el estrés oxidativo en el organismo humano ${ }^{25}$.

En el presente estudio se eligieron diabéticos tipo 1 y 2 por el impacto que esta enfermedad tiene en la población general y en los indicadores sanitarios universales. Se ha estimado que para el año $2035 \mathrm{el}$ número de diabéticos en el mundo estará próximo a los seiscientos millones de individuos ${ }^{26}$, algo que impactará globalmente en las causas de mortalidad y en los índices de prevalencia de otras enfermedades. De modo que el adecuado y oportuno manejo del control de la diabetes puede extender la calidad de vida y el pronóstico en otras patologías asociadas o intercurrentes.

Los sistemas celulares dañados en la diabetes pueden, por su parte, hacerse tóxicos en sí mismos al degradarse en otros productos igualmente dañinos para la salud celular como las ERO, que inciden en la peroxidación de las grasas polinsaturadas las que, al reaccionar con otros residuos metabólicos, como los sulfhidrilo de la cisteína, generan los productos finales de lipo-oxidación avanzada (ALE, en inglés), cuyo papel emergente en la patogénesis de procesos cardiovasculares, hepáticos y neurodegenerativos es cada vez más claro ${ }^{27}$.

La resistencia insulínica suele cursar en silencio y se manifiesta clínicamente años después de estar presente en forma de HG. Estos niveles elevados de glucosa en forma sostenida favorecen el desbalance entre la disponibilidad de óxido nítrico endotelial y la acumulación de ERO, lo cual despierta una 
cadena de eventos fisiopatológicos que conducen a la disfunción enzimática en la homeostasis endotelial y a fallas en la expresión genética de los sistemas enzimáticos reguladores, a la inflamación y al EO microvascular ${ }^{5-9,28}$. Por ejemplo, en la patogénesis de la retinopatía diabética (RPD), el metabolismo de la glucosa anómala inducida por la HG, la peroxidación lipídica, la glicación avanzada, la toxicidad del glutamato y el EO crean un sustrato donde la apoptosis de células endoteliales capilares de la retina favorece una mayor expresión del factor de crecimiento endotelial vascular (VEGF, en inglés) y su receptor tipo 2 (VEGFR2, en inglés), siendo estos los factores cruciales detrás del desarrollo de la microangiopatía diabética ${ }^{29}$.

La HG intracelular conduce a daño tisular a través de cinco grandes mecanismos ${ }^{30}$ :

1. Aumento de la expresión del receptor de productos finales de glicación avanzada (AGE, en inglés) y sus ligandos activadores.

\section{Aumento de formación intracelular de AGE}

3. Aumento del flujo de glucosa y otros azúcares a través de la vía del poliol

4. Activación de las isoformas de la proteína quinasa $\mathrm{C}(\mathrm{PKC})$

5. Sobreactividad de la vía de la hexosamina.

Estos mecanismos se activan mediante la sobreproducción mitocondrial de ERO y llevan a la microangiopatía, contrario al daño macrovascular diabético y al daño cardíaco, que ocurren por el aumento de la oxidación de los ácidos grasos debido a la resistencia insulínica ${ }^{31}$.

En pacientes diabéticos se ha encontrado una fuerte activación de la $\mathrm{PKC}$, una enzima muy vinculada al aumento en la generación de ERO que, por tanto, correlaciona con el deterioro de la seńalización de la insulina ${ }^{32}$. El p66Shc, una isoforma del gen $\mathrm{SCH}_{1}$ presente en mamíferos, participa en la regulación de los niveles de ERO, en la inducción de apoptosis, en la modulación de la migración celular endotelial y en los brotes para la angiogénesis $^{33}$. Mientras en animales diabéticos el p66Shc protege contra la disfunción endotelial y el EO inducidos por $\mathrm{HG}$, gracias a su acción reguladora sobre sistemas $\mathrm{AO}^{34}$, en humanos diabéticos la expresión genética del p66Shc está aumentada en las células mononucleares de muestras de sangre periférica y, aunque en el estudio de Fadini et al. ${ }^{35}$ no se asoció con complicaciones diabéticas prevalentes, predijo un nuevo inicio de complicaciones, especialmente macroangiopatía, y se correlacionó bien con el EO. Estos cambios podrían persistir, sobre todo el componente de la disfunción endotelial, a pesar de buenos controles glucémicos, si no hay manejo del $\mathrm{EO}$ o de los factores que inducen a cambios epigenéticos. Este fenómeno, denominado "memoria metabólica ${ }^{36 "}$ ", parece ser un determinante importante para el riesgo vascular en diabéticos que ha merecido especial atención en el presente y en el que la modulación epigenética y la reducción del EO con la aplicación de terapia antioxidante podrían representar la piedra angular en la prevención del daño vascular macroscópico en DMT2 $2^{37,38}$.

Un importante aspecto en la fisiopatología del daño endotelial lo representan las cascadas anormales provocadas por los AGE, que son un grupo heterogéneo de moléculas generadas por medio de reacciones no enzimáticas de glicación y de oxidación de proteínas, lípidos y ácidos nucleicos en condiciones de HG o de fluctuaciones de glucosa sanguínea. El EO favorece la generación de AGE, los cuales reaccionan a nivel tisular a través de numerosos receptores (RAGE) causando una exagerada respuesta inflamatoria y el consiguiente daño vascular responsable de lesiones a distintos niveles y que conducen a las complicaciones ${ }^{39}$.

Una de estas complicaciones a la que se ha prestado mucha atención recientemente es la neuropatía 
diabética (NPD), ya que con el conocimiento actual de su fisiopatogenia es posible plantearse intervenciones preventivas tempranas. Más de la mitad de los diabéticos la desarrollan, culminando en una disfunción nerviosa periférica y autonómica de grado variable que puede llevar al síndrome de pie diabético, que en muchos casos requerirá alguna forma de amputación.

La asociación del deterioro metabólico y vascular lleva a disfunción neuronal, en forma similar al daño endotelial promovido por los eventos oxidativos desencadenados en conexión con la HG, lo cual lleva a pérdida del soporte neurotrópico y, de forma crónica, provocará apoptosis en el sistema nervioso periférico ${ }^{40}$.

La producción de ERO favorecen la neuroinflamación, que se suma a la disfunción mitocondrial neuronal y axonal provocada por la HG, para concluir en una estructuración anormal de proteínas y ADN. Los factores de transcripción ayudan a regular la función mitocondrial normal y protegen los axones y las neuronas en la neuropatía diabética, los cuales se deterioran por efectos de las ERO en la diabetes, llevando a distintas complicaciones, según se ha mencionado previamente. En resumen, el EO causa daño nervioso a través de la generación de $\mathrm{ERO}$, de la peroxidación lipídica, del daño al ADN y por la reducción de los $\mathrm{AO}$ intracelulares ${ }^{41}$.

La identificación de una actividad reducida de las enzimas AO, SOD y GPx, en pacientes DMT2 con neuropatía ${ }^{42}$, permite una evaluación más precisa de su patogénesis, lo que plantea la posibilidad de un reconocimiento temprano del daño neural mediante el seguimiento a través de biomarcadores de EO y la posible prevención de la NPD.

Otro aspecto de importancia en las complicaciones derivadas de la DM es la nefropatía diabética (ND). En gran parte, el aumento de la mortalidad es debido a la alta incidencia de esta complicación del espectro diabético, que conduce a la enfermedad renal crónica. El desarrollo de la ND está condicionado por factores como susceptibilidad genética, HG, activación de las vías de poliol, activación del sistema de renina-angiotensina, activación de la vía PKC, aumento de los AGE, hiperfiltración glomerular y la producción excesiva de $\mathrm{ERO}^{43}$. En la gran mayoría de los casos los pacientes permanecen sin síntomas por meses o años, a pesar del daño histológico en progreso, lo cual impide la instalación de medidas preventivas más oportunamente.

La fisiopatología de la ND es compleja, pero generalmente comienza con cambios hemodinámicos que afectan la función glomerular, seguidos de cambios estructurales que culminan en fibrosis renal. El control deficiente de la glucemia, la hipertensión arterial, el aumento del colesterol y la activación de mediadores de inflamación y el EO favorecen el progreso de la nefropatía a etapas avanzadas de una forma relativamente rápida ${ }^{44}$. Los factores desencadenantes mejor investigados son la HG, los trastornos genéticos, la hipertensión arterial y el EO.

Los podocitos del riñón tienen receptores específicos para los AGE. La HG y la generación de AGE tienen un efecto acelerador de la filtración glomerular que lleva a hipertrofia de los glomérulos y, dentro de estos cambios, se liberan citoquinas, marcadores inflamatorios y la activación de varias vías de EO. La HG persistente asociada al incremento de los AGE es responsable de alteraciones en el sistema renina-angiotensina y en la señalización del factor de crecimiento-beta transformador (TGF- $\beta$, en inglés), produciendo inflamación crónica e hipertrofia glomerular y tubular, acompańados de otros cambios histológicos que no son más que cambios redox que facilitan la aparición de albuminuria, proteinuria, glomérulosclerosis y fibrosis tubular intersticial ${ }^{45}$. El EO en los pacientes con DM, por tanto, actúa como 
un iniciador y, según se va estableciendo, es capaz de modular y conectar intrínsecamente distintas vías en la compleja red de eventos patológicos que concurren en la ND.

En la práctica, es posible utilizar la acumulación de AGE como un marcador no invasivo para identificar la presencia de dańo tisular en DM, aunque requiere de métodos sofisticados y poco disponibles en muchos centros y no es de amplio uso en la actualidad ${ }^{46}$. La determinación de otros biomarcadores, como los productos de la peroxidación lipídica y los grupos carbonilo proteicos, aún son válidos en el diagnóstico y pronóstico de la ND, ya que el disparo inicial asociado a la generación de ERO impactan tempranamente y dejan mucha huella bioquímica ${ }^{47}$.

En fin, la literatura actual fundamenta todos estos hallazgos que asocian al EO con la fisiopatogenia de las complicaciones de la DM, para trazar estrategias farmacológicas que permitan el control de los cambios endoteliales y bloquear la inflamación vascular y el EO. Estas medidas pueden ayudar a frenar, cuando no prevenir, los desórdenes metabólicos, lo que puede garantizar la restauración de la fisiología molecular y la reorganización capilar, así como una mayor entrega y mejor sensibilidad insulínica tisular, de modo que se puedan ofrecer mejores pronósticos gracias a una evolución más favorable de la enfermedad y un menor impacto de las complicaciones.

Las múltiples complicaciones asociadas con DM se relacionan estrechamente con los excesos de ERO, fundamentos bioquímicos del EO, en presencia de condiciones que alteran las funciones $\mathrm{AO}$ del organismo en un círculo vicioso que se repetirá una y otra vez, hasta tanto este no se rompa. Conceptualmente, si el EO es alto, el daño a las biomoléculas clave en la DMT2 podría evitarse con la reversión del desequilibrio a través de medidas como el control entre el estado glucémico y la generación de radicales libres.
Cualquier sustancia o sistema que inhiba o reduzca la oxidación de un sustrato se considera un antioxidante. Algunos $\mathrm{AO}$ se producen endógenamente, pero una gran mayoría viene de fuentes externas a través de los alimentos, entre los cuales se señalan las frutas, vegetales, cereales, champiñones, especias y flores, y plantas medicinales debidamente identificadas y cuyos productos, más modernamente, gozan de un alto grado de clasificación y procesamiento $^{48}$.

Los $\mathrm{AO}$ son considerados agentes de defensa y están representados por sistemas enzimáticos y no enzimáticos, entre los cuales se destacan las vitaminas A, C y E, el glutatión, las enzimas SOD, CAT y GSH-reductasa; también se incluyen el ácido $\alpha$-lipoico, la coenzima $\mathrm{Q}_{10}$, algunos bioflavonoides, ciertos cofactores (ácido fólico, vitaminas $\mathrm{B}_{1}, \mathrm{~B}_{2}$, $\mathrm{B}_{6}, \mathrm{~B}_{12}$ ), y minerales con actividad $\mathrm{AO}$ (cobre, zinc, selenio y manganeso $)^{49}$. Los $\mathrm{AO}$ que provienen de fuentes naturales, y algunos del procesamiento industrial, son, generalmente, polifenoles (ácidos fenólicos, los flavonoides, las antocianinas, los lignanos y los estilbenos) y vitaminas. Se reconoce principalmente a los polifenoles y carotenoides como los AO de mayor impacto biológico, en especial en la inflamación, la senescencia y el cáncer ${ }^{50}$.

La sobreproducción de ERO rompe el balance entre los sistemas $\mathrm{AO}(\mathrm{SAO})$ o el propio daño de los $\mathrm{SAO}$ causa la producción excesiva, no manejable, de ERO. Los SAO pueden ser medidos y ponderados para estimar el nivel de daño causado por el EO, lo que se conoce como Índice de EO (IEO) y los productos de los $\mathrm{SAO}$ se titulan como biomarcadores para medir el IEO. Núńez-Musa et al. ${ }^{51}$ comprobaron que el IEO era altamente significativo $(\mathrm{p}<0.05)$ en pacientes con hipertensión arterial grado II o superior en pacientes dominicanos, comparados con grupos sanos y con casos de hipertensión arterial de menor severidad. Por tanto, es posible que un aumento en la ingesta de $\mathrm{AO}$ exógenos tenga un efecto atenuador del daño causado por el EO por inhibir el inicio o la propa-

84 | Ciencia y Salud 2020; 4(3, septiembre-diciembre): Casos clínicos • 71-93 
gación de las reacciones de la cadena oxidativa en exceso, al actuar como "inactivadores" de radicales libres y extintores de la propagación de las reacciones oxidativas, por lo que los $\mathrm{AO}$ pueden ser usados en forma terapéutica o preventiva, según sea su mecanismo de acción.

Muchos estudios se han llevado a cabo en los últimos treinta años para identificar cuáles $\mathrm{AO}$ son los más efectivos para revertir o detener el EO, con muy variados resultados, pero en la mayoría de ellos no se descarta la posibilidad de su uso dentro de los protocolos terapéuticos de las enfermedades.

En el caso de la DM, la atención debe centrarse en identificar los biomarcadores asociados al desarrollo de complicaciones o comorbilidades y los $\mathrm{AO}$ candidatos a revertir sus efectos. Por ejemplo, las vitaminas $\mathrm{C}$ y $\mathrm{E}$ pueden proteger contra la aparición de RPD; la benfotiamina, un análogo lipofílico del monofosfato de tiamina, puede proteger a las células vasculares del daño metabólico inducido por la HG y resguardar a los pericitos retinianos de la apoptosis, mediante la normalización del índice $\mathrm{Bcl}-2 / \mathrm{Bax}^{52}$.

La poli ADP-ribosa polimerasa (PARP, en inglés) es un mediador del daño oxidativo que aumenta la expresión de factores vasoactivos y la producción de proteínas de matriz extracelular en animales diabéticos, lo cual constituye parte de los mecanismos patológicos envueltos en la ND. El uso de la benfotiamina ha probado utilidad en bloquear al PARP y normalizar estos cambios ${ }^{53}$.

El SOD, la CAT y las NO sintetasas se consideran las enzimas $\mathrm{AO}$ más importantes para la protección del riñón contra los ERO. Estas enzimas forman parte de los sistemas antioxidantes endógenos, pero su síntesis puede ser inducida con terapias diversas, como por ejemplo la que utiliza ozono $^{54}$. Particularmente, la SOD reacciona con el superóxido para generar peróxido de hidrógeno, que es degradado por la CAT y el GPx. Gracias a su acción bioquímica, el SOD ayuda a suprimir la albuminuria, los niveles de TGF- $\beta$, la síntesis de colágeno y el $\mathrm{EO}$ en modelos experimentales ${ }^{55}$. En un estudio reciente, la curcumina, mayor ingrediente activo de la cúrcuma, fue capaz de reducir $o$ atenuar la proteinuria en ND relacionado con el bloqueo de citoquinas, particularmente la TGF- $\beta$ y la IL-8 ${ }^{56}$. Estos datos sugieren que, en un futuro muy próximo, el control del desarrollo o la progresión de la ND dependerán, en gran parte, de una terapia $\mathrm{AO}$ adyuvante a los esquemas tradicionales.

Por la estrecha relación del EO y la NPD, los AO van ocupando un sitio relevante entre las principales corrientes de terapia antidiabética en la última década. Es imprescindible combatir la disfunción nerviosa en la diabetes y para ello un número cada vez mayor de $\mathrm{AO}$ y agentes que imitan $\mathrm{AO}$ se han probado in vivo e in vitro en modelos experimentales con animales. Ensayos clínicos en humanos con ácido alfa-lipoico (ALA, en inglés) han probado efectividad al reducir los síntomas o el progreso de la $\mathrm{NPD}^{57}$. En otras pruebas de laboratorio el resveratrol ha probado ser efectivo como antioxidante y antiinflamatorio, contribuyendo en forma relevante en la neuroprotección contra la NPD ${ }^{58}$. En diseńos dirigidos a controlar y detener el proceso inflamatorio tisular, la vitamina $\mathrm{E}$ ha mostrado buenos resultados en animales de laboratorio, lo mismo que el derivado sintético metil-bardoxolona, que hasta ahora ha resultado altamente eficaz para frenar el EO y la inflamación ${ }^{59}$. La mayor parte de estos estudios requieren de más experiencias en modelos distintos de observación.

Los estudios con AO para el manejo coadyuvante de muy diversas entidades nosológicas vienen realizándose por décadas. Los modelos de estudio han variado con los años producto de las innovaciones farmacéuticas y del mayor y mejor conocimiento de la genética humana y la patogénesis de las enfermedades, entre otros aspectos no menos importantes. Hay numerosos resultados positivos acerca 
del uso de AO como parte de las terapias convencionales de la diabetes y otras enfermedades que incluyen a las vitaminas $\mathrm{A}, \mathrm{C}$, y E, la curcumina, el ALA, la melatonina, la acetil-L-carnitina y los flavonoides.

El ALA es un antioxidante natural que cumple con todos los criterios para un agente ideal para asociarse al tratamiento de diversas enfermedades relacionadas con el EO. Solo o asociado muestra efectividad y especificidad en su acción AO. En un estudio reciente, una combinación de ALA con CoQ10 mostró excelentes resultados en la atenuación de la NPD y en la dramática supresión de la neuropatía inducida por el EO ( $\mathrm{p}<0.05)$, lo que ha dado soporte a su abierta recomendación en asociación al uso de antidiabéticos ${ }^{60}$. Tal vez, uno de sus más importantes efectos en la contención del dańo oxidativo lo representa su capacidad para reforzar la acción desintoxicante del organismo contra los principales precursores de AGE, según resultados de estudios de laboratorio ${ }^{61}$. A pesar de estos reportes, solo el ALA ha sido introducido y aprobado como parte del esquema de tratamiento en DM en algunos países de Europa. Esto sugiere que la suplementación de $\mathrm{AO}$ debe ser valorada como una terapia adyuvante en DMT2, pues se espera que un fortalecimiento de los mecanismos de defensa $\mathrm{AO}$ (desintoxicante) reducirá el EO o sus consecuencias y ayudará a ralentizar o prevenir los cambios vasculares que conducen a complicaciones. Contrariamente a la abrumadora evidencia existente en la actualidad, no se ha logrado un consenso en este aspecto.

Los estudios en animales han demostrado que el uso de $\mathrm{AO}$ puede ser una estrategia terapéutica beneficiosa en el manejo antidiabético. De los AO que han progresado a ensayos clínicos en humanos, pocos se encuentran actualmente en diferentes etapas de evaluación y, en otros casos, no ha sido posible replicar en pruebas con humanos los resultados obtenidos en animales de laboratorio, a pesar de identificarse claramente sus mecanismos de intermediación en la cascada oxidativa.
En suma, los AO actúan a favor del restablecimiento de la homeostasis oxidativa por dos vías principales: una, por la reducción los efectos nocivos de los radicales libres, lo cual pueden hacer por inhibición de su formación o por la inactivación de los ya generados; otra, potenciando los sistemas de defensa naturales mediante la estimulación de la actividad enzimática antioxidante y regenerando otras proteínas implicadas en las vías $\mathrm{AO}$. Sin embargo, la elección de la estrategia depende del tipo, estructura y concentración de los $\mathrm{AO}$, de los biomarcadores específicamente alterados y de la evolución clínica y las causas primarias de la enfermedad.

La prevención o la detención de las comorbilidades en la DM puede que descanse en un futuro en la identificación precisa de los biomarcadores y su contrapartida reguladora. Sin embargo, no es tan sencillo como asegurar suplementos dietéticos de forma meticulosamente balanceada, sobre todo para pacientes que ingieren dosis insuficientes, o elevar la carga de alimentos, ya que posiblemente la ingestión de nutrientes sobreagregados no ofrecerá beneficios adicionales. No debe ser así, pues hay muchos fenómenos colaterales que tienen lugar a lo largo de la vida. Las agresiones externas, que promueven cambios epigenéticos que se trasmiten generacionalmente, la edad, el sexo, el estado de salud y la estructuración psicológica del paciente determinan el grado y tipo de adhesión a los regímenes terapéuticos y en ninguno de ellos la dieta, por sí sola, aun siendo esta estricta y supervisada, podría garantizar niveles adecuados de $\mathrm{AO}$ en el momento preciso y del tipo requerido. De modo que la complementación terapéutica precisa con $\mathrm{AO}$ específicos jugará el mayor rol favorecedor de mejores pronósticos en los pacientes diabéticos.

En el presente estudio, el GDO en el subgrupo IIa fue ponderado como ligero, mientras que en el subgrupo IIb fue moderado, lo que sugiere que una terapia utilizando un protocolo con $\mathrm{AO}$ adyuvantes al manejo estándar de la DMT2 podría proveer 
resultados más eficaces para el control hiperglucémico y, por tanto, para inducir el equilibrio redox. Asimismo, es imperativo conocer la extensión y tipo de dańo oxidativo de las poblaciones específicas, mediante la creación y utilización de una línea de base con los biomarcadores más frecuentemente alterados, ya que esto permitirá definir la mejor estrategia antioxidante a aplicar ${ }^{7-9,25}$. Esto es así, porque el polimorfismo genético, el ambiente y los hábitos de vida son muy determinantes en el tipo de respuesta de los SAO de los individuos. Thakur y Rachana ${ }^{59}$ opinan que es importante desarrollar nuevas combinaciones de dosis fijas de $\mathrm{AO}$ eficaces dirigidos las fuentes clave de producción de ERO, similares a los SAO endógenos y capaces de eliminar las especies reactivas para lograr el restablecimiento del equilibrio entre los pro-oxidantes y los AO.

El desarrollo de nuevos fármacos con efectos $\mathrm{AO}$ o capaces de reforzar el SAO a partir de sustratos naturales, asegura alternativas de alto valor terapéutico, como el caso de la mangiferina. Núnez-Sellés $^{62}$ ha destacado el amplio espectro de acción dentro del sistema $\mathrm{AO}$ y su prometedora efectividad para la reversión del daño, pero, al presente, el compuesto necesita de una evaluación estandarizada de su eficacia, de su farmacodinamia y del aseguramiento de la calidad.

Debe destacarse que los resultados obtenidos en el grupo IIa (DMT1) no aconsejan la aplicación de una terapia $\mathrm{AO}$ en esta población de diabéticos, ya que la ponderación del daño oxidativo resultó leve $y$, en tales casos, la respuesta funcional del organismo puede estar mejor balanceada que en los casos de DMT2. Escobar et al. ${ }^{63}$ no obtuvieron resultados significativos $(p>0.05)$ en un protocolo antioxidante clínico en DMT1. Por tanto, el diagnóstico del tipo de DM deberá ser tomado en cuenta en la decisión de la intervención terapéutica con AO. Para muchos autores, las terapias AO agregadas a los tratamientos antidiabéticos estándar pueden mejorar la supervivencia y reducir las comorbilidades, algo que con el solo control de la HG no se ha obtenido ${ }^{12,53,64}$.

Un diagnóstico del EO, basado en la escala porcentual, se fundamenta en el estado oxidativo de una población particular de edad específica, en este caso portadores de DM. El grupo de estudio fue comparado con un grupo control equilibrado por edad sin DM, lo que significa que el IEO reflejaría el EO relacionado por sí solo con la enfermedad en grupos comparables. Los resultados analíticos del presente estudio no pueden extrapolarse a otras poblaciones de edad u orígenes geográficos distintos, cuya línea de base para los biomarcadores del EO sean desconocidos.

El objetivo de este ensayo clínico fue demostrar cómo, con mediciones relativamente sencillas de un grupo de biomarcadores del EO, se expresan las respuestas del organismo humano a factores externos y/o internos ante fenómenos desequilibrantes de la homeostasia y se convierten en una herramienta útil para demostrar el papel o la relación entre estos biomarcadores y la fisiopatología de una enfermedad, que para el caso actual es la DM.

Más estudios y más tiempo de observación en trabajos futuros podrán dotar de métodos estandarizados de medición para apoyar el diagnóstico temprano de muchas enfermedades crónicas o de sus complicaciones mediante tamizajes confiables para EO versus riesgo de enfermedad.

\section{Conclusiones}

La DM puede dañar los ojos, los riñones, los nervios y el corazón, a través de trastornos microvasculares y macrovasculares asociados a la HG y EO y los biomarcadores del EO permiten evaluar el estado de progreso de la enfermedad. Los AO son un recurso útil para mejorar el cuadro clínico y el pronóstico de los pacientes por su potencial capacidad de prevenir y reparar estos daños. Los resultados del ensayo conducen a la hipótesis 
de que con un diagnóstico adecuado del EO, es posible perfeccionar una intervención terapéutica en la DMT2 con el uso de un cóctel de antioxidantes basado en la determinación estandarizada del IEO. Esto permitirá la selección óptima de los AO idóneos para su uso dentro de los esquemas tradicionales de tratamiento antidiabético, con el fin de aumentar la eficacia terapéutica y disminuir las comorbilidades.

Hasta la fecha, a pesar de gran parte del debate, el uso cada vez mayor de $\mathrm{AO}$ más las terapias antidiabéticas estandarizadas parece ser la forma más eficaz de mejorar el pronóstico en DMT2, ya que los mecanismos moleculares implicados en la regulación de la función vascular, el equilibrio metabólico y el estado redox pueden ser controlados o revertidos cuando se manejan adecuadamente por medio de productos $\mathrm{AO}$ específicos. El uso del IEO con distintos marcadores ayuda a la especificidad del diagnóstico oxidativo, pero para que la elección de los marcadores sea la correcta, esta debe estar definida por el objetivo y el diseño del estudio, así como por la relevancia clínica en los sujetos seleccionados, tal cual fue el aplicado en este ensayo. En tal sentido, los hallazgos no apoyan la implementación de una terapia AO en DMT1. Finalmente, la importancia clínica de los biomarcadores del EO en humanos debe provenir de un análisis crítico de los marcadores que refleje el estado general de redox en condiciones particulares y una orientación para una terapia antioxidante efectiva.

\section{Agradecimientos}

El soporte financiero del Proyecto FONDOCYT 2012-2013-2A1-58, del Ministerio de Educación Superior, Ciencia y Tecnología de la República Dominicana, es altamente agradecido. A R. Silverio, D.A. Terrero y M. Beras por su apoyo en el reclutamiento de casos en los hospitales. D. Jackson, L. Kelly, J.M. Jiménez, L. Pérez por su asistencia en el reclutamiento de los voluntarios sanos. M. Butler y P. Santana por el soporte logístico en la Facultad de Ciencias de la Salud, de la Universidad Nacional Evangélica (UNEV).

\section{Conflicto de intereses}

Los autores no reportan conflicto de intereses.

\section{Bibliografía}

1. Valdespino-Gómez V, Valdespino-Castillo P, Valdespino-Castillo V. Interacción de las vías de señalización intracelulares participantes en la proliferación celular: potencial blanco de intervencionismo terapéutico. Cirugía y Cirujanos. 2015;83(2):165-174. Doi: 10.1016/j. circir.2015.04.015

2. Baba SP, Bhatnagar A. Role of Thiols in Oxidative Stress. Current Opinion in Toxicology. 2018;7, 133-139. Doi: 10.1016/j.cotox.2018.03.005

3. Yang H, Jin X, Kei Lam C, Yan S. Oxidative stress and diabetes mellitus. Clinical Chemistry and Laboratory Medicine. 2011;49(11). Doi: $10.1515 / \mathrm{cclm} .2011 .250$

4. Di Meo S, Reed T, Venditti P, Victor V. Role of ROS and RNS Sources in Physiological and Pathological Conditions. Oxidative Medicine and Cellular Longevity. 2016;2016:1-44. Doi: $10.1155 / 2016 / 1245049$

5. Gerber P, Rutter G. The Role of Oxidative Stress and Hypoxia in Pancreatic Beta-Cell Dysfunction in Diabetes Mellitus. Antioxidants \& Redox Signaling. 2017;26(10):501-18. Doi: 10.1089/ ars. 2016.6755

6. Lipinski B. Pathophysiology of oxidative stress in diabetes mellitus. Journal of Diabetes and its Complications. 2001;15(4):203-210. Doi: $10.1016 / s 1056-8727(01) 00143-\mathrm{x}$ 
7. Maritim A, Sanders R, Watkins J. Diabetes, oxidative stress, and antioxidants: A review. Journal of Biochemical and Molecular Toxicology. 2003;17(1):24-38. Doi: 10.1002/ jbt. 10058

8. Pouvreau C, Dayre A, Butkowski E, de Jong $\mathrm{B}$, Jelinek H. Inflammation and oxidative stress markers in diabetes and hypertension. Journal of Inflammation Research. 2018;11:61-8. Doi: 10.2147/jir.s148911

9. Butkowski E, Jelinek H. Hyperglycaemia, oxidative stress and inflammatory markers. Redox Report. 2016;22(6):257-64. Doi: $10.1080 / 13510002.2016 .1215643$

10. American Diabetes Association. Pharmacologic Approaches to Glycemic Treatment: Standards of Medical Care in Diabetes_2019. Diabetes Care. 2018;42(Supplement 1):S90-S102. Doi: $10.2337 / \mathrm{dc} 19-\mathrm{s} 009$

11. Robles-Rivera R, Castellanos-González J, Olvera-Montańo C, Flores-Martin R, López-Contreras A, Arevalo-Simental D et al. Adjuvant Therapies in Diabetic Retinopathy as an Early Approach to Delay Its Progression: The Importance of Oxidative Stress and Inflammation. Oxidative Medicine and Cellular Longevity. 2020;2020:1-23. Doi: $10.1155 / 2020 / 3096470$

12. Zhang P, Li T, Wu X, Nice E, Huang C, Zhang Y. Oxidative stress and diabetes: antioxidative strategies. Frontiers of Medicine. 2020. Doi: 10.1007/s11684-019-0729-1

13. Pichardo R, González A, Ramírez W, Escaño F, Rodríguez C, Jiménez R et al. Estudio de los Factores de Riesgo Cardiovascular y Síndrome Metabólico en la República Dominicana (EFRICARD II). Revespcardiol.org. 2012. Disponible en: https://tinyurl.com/uys89nr [Acesso 10 abril 2020]
14. Özdemirler G, Mehmetçik G, Öztezcan S, Toker G, Sivas A, Uysal M. Peroxidation Potential and Antioxidant Activity of Serum in Patients with Diabetes Mellitus and Myocardial Infarction. Hormone and Metabolic Research. 1995;27(04):194-6. Doi: 10.1055/s-2007979938

15. Erel O. A novel automated direct measurement method for total antioxidant capacity using a new generation, more stable ABTS radical cation. Clinical Biochemistry. 2004;37(4):277-85. Doi: 10.1016/j.clinbiochem.2003.11.015

16. Kedare SB, Singh RP. Genesis and development of DPPH method of antioxidant assay. J Food Sci Technol. 2011;48(4):412-22. Doi:10.1007/s13197-011-0251-1

17. Esterbauer H, Cheeseman K. Determination of aldehydic lipid peroxidation products: Malonaldehyde and 4-hydroxynonenal. Oxygen Radicals in Biological Systems Part B: Oxygen Radicals and Antioxidants. 1990;407-21. Doi: 10.1016/0076-6879(90)86134-h

18. Oliver CN, Ahn BW, Moerman EJ, Goldstein S, Stadtman ER. Age-related changes in oxidized proteins. J Biol Chem. 1987;262(12):5488-91

19. Sedlak J, Lindsay RH. Estimation of total, protein-bound, and nonprotein sulfhydryl groups in tissue with Ellman's reagent. Anal Biochem. 1968;25(1):192-205. Doi:10.1016/00032697(68)90092-4

20. Del Mestro R, McDonald W. Oxidative enzymes in tissue homogenates. En: Greenwald R, ed. Handbook for Oxygen Radical Research. Boca Raton, FL: CRC Press; 2018. p. 291-296.

21. Haining J, Legan J. Improved assay for catalase based upon steady-state substrate concentration. Analytical Biochemistry. 1972;45(2):46979. Doi: 10.1016/0003-2697(72)90209-6 
22. Gil L, Martínez G, González I, Tarinas A, Alvarez A, Giuliani A et al. Contribution to characterization of oxidative stress in HIV/AIDS patients. Pharmacological Research. 2003;47(3):217-24. Doi: $10.1016 / s 1043-6618(02) 00320-1$

23. Sas K, Szabó E, Vécsei L. Mitochondria, Oxidative Stress and the Kynurenine System, with a Focus on Ageing and Neuroprotection. Molecules. 2018;23(1):191. Doi: 10.3390/molecules 23010191

24. Frijhoff J, Winyard PG, Zarkovic N, Davies SS, Stocker R, Cheng D, Knight AR, Taylor EL, Oettrich J, Ruskovska T, Gasparovic AC. Clinical relevance of biomarkers of oxidative stress. Antioxidants \& redox signaling. 2015;23(14):1144-70. Disponible en https:// doi.org/10.1089/ars.2015.6317

25. Marrocco I, Altieri F, Peluso I. Measurement and clinical significance of biomarkers of oxidative stress in humans. Oxidative medicine and cellular longevity. 2017;2017. Disponible en https://doi.org/10.1155/2017/6501046

26. Guariguata L, Whiting DR, Hambleton I, Beagley J, Linnenkamp U, Shaw JE. Global estimates of diabetes prevalence for 2013 and projections for 2035. Diabetes Res Clin Pract. 2014;103:137-49. Doi: 10.1016/j. diabres.2013.11.002

27. Butterfield D, Dalle-Donne I. Redox proteomics: from protein modifications to cellular dysfunction and disease. Mass Spectrometry Reviews. 2013;33(1):1-6. Doi: 10.1002/ mas. 21404

28. Giacco F, Brownlee M. Oxidative stress and diabetic complications. Circulation Research, 2010;107(9), 1058-70. Disponible en doi. org/10.1161/CIRCRESAHA.110.223545
29. Mondal LK, Bhaduri G, Bhattacharya B. Biochemical scenario behind initiation of diabetic retinopathy in type 2 diabetes mellitus. Indian J Ophthalmol. 2018;66(4):535-40. Doi:10.4103/ijo.IJO_1121_17

30. Rahimi-Madiseh M, Malekpour-Tehrani A, Bahmani M, Rafieian-Kopaei M. The research and development on the antioxidants in prevention of diabetic complications. Asian Pacific Journal of Tropical Medicine. 2016;9(9):825-31. Doi: 10.1016/j.apjtm.2016.07.001

31. Brownlee M. The Pathobiology of Diabetic Complications: A Unifying Mechanism. Diabetes. 2005;54(6):1615-25. Doi: 10.2337/ diabetes.54.6.1615

32. Tabit C, Shenouda S, Holbrook M, Frame A, Kluge M, Duess M et al. Protein Kinase-C Beta Activation Contributes to Impaired Endothelial Insulin Signaling in Humans with Diabetes Mellitus. Journal of the American College of Cardiology. 2012;59(13):E2133. Doi: 10.1016/s0735-1097(12)62134-2

33. Audero E, Cascone I, Maniero F, Napione L, Arese M, Lanfrancone L, Bussolino F. Adaptor ShcA protein binds tyrosine kinase Tie2 receptor and regulates migration and sprouting but not survival of endothelial cells. J Biol Chem. 2004;279(13), 13224-33. Doi: 10.1074/jbc.M307456200

34. Camici G, Schiavoni M, Francia P, Bachschmid M, Martin-Padura I, Hersberger $M$ et al. Genetic deletion of p66Shc adaptor protein prevents hyperglycemia-induced endothelial dysfunction and oxidative stress. Proceedings of the National Academy of Sciences. 2007;104(12):5217-22. Doi: 10.1073/ pnas.0609656104 
35. Fadini G, Albiero M, Bonora B, Poncina N, Vigili de Kreutzenberg S, Avogaro A. p66Shc gene expression in peripheral blood mononuclear cells and progression of diabetic complications. Cardiovascular Diabetology. 2018;17(1). Doi: 10.1186/s12933-018-0660-9

36. Ceriello A. The emerging challenge in diabetes: The "metabolic memory". Vascular Pharmacology. 2012;57(5-6):133-8. Doi: 10.1016/j. vph.2012.05.005

37. CooperME, El-OstaA.Epigenetics: mechanisms and implications for diabetic complications. Circulation Research. 2010;107(12):1403-13. Doi: 10.1161/CIRCRESAHA.110.223552.49

38. Paneni F, Costantino S, Volpe M, Luscher TF, Cosentino F. Epigenetic signatures and vascular risk in type 2 diabetes: a clinical perspective. Atherosclerosis. 2013;230(2):191-7. Doi: 10.1016/j.atherosclerosis.2013.07.003

39. Singh VP, Bali A, Singh N, Jaggi AS. Advanced glycation end products and diabetic complications. Korean J Physiol Pharmacol. 2014;18(1):1-14. Doi:10.4196/ kjpp.2014.18.1.1

40. Schmeichel A, Schmelzer J, Low P. Oxidative Injury and Apoptosis of Dorsal Root Ganglion Neurons in Chronic Experimental Diabetic Neuropathy. Diabetes. 2003;52(1):165-71. Doi: $10.2337 /$ diabetes.52.1.165

41. Edwards JL, Vincent AM, Cheng HT, Feldman EL. Diabetic neuropathy: mechanisms to management. Pharmacology \& therapeutics. 2008 Oct 1;120(1):1-34. Disponible en https://doi. org/10.1016/j.pharmthera.2008.05.005

42. Kasznicki J, Kosmalski M, Sliwinska A, Mrowicka M, Stanczyk M, Majsterek I, Drzewoski J. Evaluation of oxidative stress markers in pathogenesis of diabetic neuro- pathy. Molecular Biology Reports. 2012 Sep 1;39(9):8669-78. Disponible en https://doi. org/10.1007/s11033-012-1722-9

43. Ziyadeh F, Hoffman B, Han D, Iglesias-de la Cruz $\mathrm{M}$, Hong $\mathrm{S}$, Isono $\mathrm{M}$ et al. Longterm prevention of renal insufficiency, excess matrix gene expression, and glomerular mesangial matrix expansion by treatment with monoclonal antitransforming growth factor-beta antibody in $\mathrm{db} / \mathrm{db}$ diabetic mice. Proceedings of the National Academy of Sciences. 2000;97(14):8015-20. Doi: 10.1073/ pnas. 120055097

44. Friedman R, Gross JL. Evolution of glomerular filtration rate in proteinuric NIDDM patients. Diabetes Care. 1991;14(5):355-9. Doi:10.2337/diacare.14.5.355.

45. De Boer IH, Rue TC, Hall YN, Heagerty PJ, Weiss NS, Himmelfarb J. Temporal trends in the prevalence of diabetic kidney disease in the United States. JAMA. 2011;305(24):2532-9. Doi:10.1001/jama.2011.861

46. Miranda-Díaz A, Pazarín-Villaseñor L, Yanowsky-Escatell F, Andrade-Sierra J. Oxidative Stress in Diabetic Nephropathy with Early Chronic Kidney Disease. Journal of Diabetes Research. 2016;2016:1-7. Doi: 10.1155/2016/7047238

47. Forbes JM, Coughlan MT, Cooper ME. Oxidative stress as a major culprit in kidney disease in diabetes. Diabetes. 2008 Jun 1;57(6):1446-54. Disponible en https://doi.org/10.2337/db080057

48. Xu D, Li Y, Meng X, Zhou T, Zhou Y, Zheng $\mathrm{J}$ et al. Natural Antioxidants in Foods and Medicinal Plants: Extraction, Assessment and Resources. International Journal of Molecular Sciences. 2017;18(1):96. Doi: 10.3390/ ijms18010096 
49. Zhou Y, Zheng J, Li Y, Xu D, Li S, Chen Y et al. Natural Polyphenols for Prevention and Treatment of Cancer. Nutrients. 2016;8(8):515. Doi: $10.3390 /$ nu 8080515

50. Núñez-Musa R, Núñez-Sellés A, Mañón Rossi W, Marmolejos R, Martínez-Sánchez G. Correlación entre el grado de hipertensión arterial y el índice de estrés oxidativo. Estudio de cohorte en una población de pacientes hipertensos sistémicos en República Dominicana. Ciencia y Salud. 2019;3(2):17-33. Doi: 10.22206/ cysa.2019.v3i2.pp17-33

51. Li C, Miao X, Li F, Wang S, Liu Q, Wang $\mathrm{Y}$ et al. Oxidative Stress-Related Mechanisms and Antioxidant Therapy in Diabetic Retinopathy. Oxidative Medicine and Cellular Longevity. 2017;2017:1-15. doi: 10.1155/ $2017 / 9702820$

52. Xu B, Chiu J, Feng B, Chen S, Chakrabarti S. PARP activation and the alteration of vasoactive factors and extracellular matrix protein in retina and kidney in diabetes. Diabetes/Metabolism Research and Reviews. 2008;24(5):40412. Doi: $10.1002 / \mathrm{dmrr} .842$

53. Braidy N, Izadi M, Sureda A, Jonaidi-Jafari N, Banki A, Nabavi $S$ et al. Therapeutic relevance of ozone therapy in degenerative diseases: Focus on diabetes and spinal pain. Journal of Cellular Physiology. 2017;233(4):2705-14. Doi: $10.1002 /$ jcp.26044

54. Samuni AM, DeGraffW, Krishna MC, Mitchell JB. Cellular sites of $\mathrm{H} 2 \mathrm{O} 2$-induced damage and their protection by nitroxides. Biochimica et Biophysica Acta (BBA)-General Subjects. 2001 Feb 16;1525(1-2):70-6. Disponible en https:// doi.org/10.1016/S0304-4165(00)00172-0
55. Shahidi S, Vanaie A, Iraj B, Siadat Z, Kabirzade M, Shakiba F et al. Curcumin as a major active component of turmeric attenuates proteinuria in patients with overt diabetic nephropathy. Journal of Research in Medical Sciences. 2019;24(1):77. Doi: 10.4103/jrms. jrms_1055_18

56. Ziegler D, Low P, Litchy W, Boulton A, Vinik A, Freeman $\mathrm{R}$ et al. Efficacy and Safety of Antioxidant Treatment With $\alpha$-Lipoic Acid Over 4 Years in Diabetic Polyneuropathy. Diabetes Care. 2011;34(9):2054-60. Doi: $10.2337 / \mathrm{dc} 11-0503$

57. Kumar A, Sharma S. NF- $x B$ inhibitory action of resveratrol: A probable mechanism of neuroprotection in experimental diabetic neuropathy. Biochemical and Biophysical Research Communications. 2010;394(2):360-5. Doi: 10.1016/j.bbrc.2010.03.014

58. Thakur S, Rachana. Antioxidants: Futuristic Therapeutics in the Field of Diabetic Neuropathy. International Journal of Biotechnology and Bioengineering Research. 2013;4(4):313-20

59. Sadeghiyan Galeshkalami N, Abdollahi M, Najafi R, Baeeri M, Jamshidzade A, Falak R et al. Alpha-lipoic acid and coenzyme Q10 combination ameliorates experimental diabetic neuropathy by modulating oxidative stress and apoptosis. Life Sciences. 2019;216:101-10. Doi: $10.1016 /$ j.lfs.2018.10.055

60. Biesalski HK, Grune T, Tinz J, Zöllner I, Blumberg JB. Reexamination of a meta-analysis of the effect of antioxidant supplementation on mortality and health in randomized trials. Nutrients. 2010;2(9):929-49. Doi: 10.3390/ nu2090929 
61. Núnez-Sellés A. Antioxidant therapy: myth or reality? Journal of the Brazilian Chemical Society. 2005;16(4):699-710. Doi: 10.1590/ s0103-50532005000500004

62. Escobar AAL, Pérez OY, Vera GM, et al. Effect of Vimang supplementation on oxidative stress markers in young patients with type 1 diabetes mellitus. Revista Cubana de Endocrinología. 2011;22(2):103-17
63. Folli F, Corradi D, Fanti P, Davalli A, Paez A, Giaccari A et al. The Role of Oxidative Stress in the Pathogenesis of Type 2 Diabetes Mellitus Micro- and Macrovascular Complications: Avenues for a Mechanistic-Based Therapeutic Approach. Current Diabetes Reviews. 2011;7(5):313-24. Doi: $10.2174 / 157339911797415585$ 